\title{
Meeting the Communicative Rights of People with Autism - Using Pictorial Supports During Assessment, Intervention and Hospital Care
}

\author{
Gunilla Thunberg, Magdalena Johansson and \\ Julia Wikholm \\ Additional information is available at the end of the chapter \\ http://dx.doi.org/10.5772/59838
}

\section{Introduction}

The main purpose of this chapter is to describe how assessment, intervention and hospital visits more generally can be managed to meet the communicative rights of people with autism spectrum disorders and improve aspects of activity and participation. A working model, built upon the United Nations conventions on the Rights of the child [1] and the Rights of persons with disability [2], using the principle of universal design [2] and augmentative and alternative communication (AAC) methods was developed within the project KomHIT-communication support in paediatric and dental care. An evaluation of this model in the form of a focus group interview with a multiprofessional team at a neuropsychiatric clinic will also be presented alongside with the examples of the pictorial supports that were used.

\section{Communication problems and communication rights in clinical settings}

\subsection{Communication in children with Autism Spectrum Disorders (ASD)}

Major advances have been made over the two past decades in understanding the socialcommunication difficulties of children with ASD, resulting in greater emphasis on early socialcommunication features in the diagnostic criteria. Most parents of children with autism first begin to be concerned that something is not quite right in their child's development because of early delays or regressions in the development of speech [3]. Problems with communication, in terms of both understanding and expression, are often said to be one of the main causes of 
the severe behaviour problems that are common among persons with severe autism and mental retardation [4].

Although all persons diagnosed with autism have problems with communication, their type and degree vary a lot and the work of identifying different subgroups has just begun. It has been estimated that between one-third [5] and one-half [6] of children and adults with autism have no speech. However, more recent research results indicate that the proportion of nonspeaking children with ASD is much smaller, approximately $14 \%$ to $20 \%$, among those who received very early intervention [7]. In spite of the heterogeneity of language abilities in children with ASD, social-communication or pragmatic impairments are universal across all ages and ability levels [8]. Certainly, communication and communication problems are at the heart of what ASD is all about

\subsection{Communication rights of persons with disability}

All individuals, with or without disabilities, have a basic human right to influence their own living conditions through communication. The United Nations' (UN's) convention on the rights of persons with disabilities, has the purpose to promote, protect and ensure the full and equal enjoyment of all human rights and fundamental freedoms by all persons with disabilities, and to promote respect for their inherent dignity. (DS 2008:23) [2]. The convention is built on eight general principles, for example: individual autonomy including the freedom to make one's own choices, full and effective participation and inclusion in society and accessibility, and respect for the evolving capacities of children with disabilities and respect for the right of children with disabilities to preserve their identities. Article 25 postulates that health professionals are required to provide care of the same quality to persons with disabilities as to others and to take all appropriate measures to ensure access. According to article 21 this includes the freedom to seek, receive and impart information and ideas on an equal basis with others and through all forms of communication of their choice, including augmentative and alternative communication. Furthermore, the idea of "Universal design" is put forth, meaning that the design of products, environments, programmes and services should be usable by all people, to the greatest extent possible, without the need for adaptation or specialized design [2].

\subsection{Communication and communication problems in health care situations}

People with disability often have many health contacts. According to Mahon and Kibirige [9] children with disability more frequently are in need of health care and are cared for longer than children without disabilities. Due to the communication difficulties being part of the autism spectrum visits to health care or hospital stays can be very problematic. Children with ASD are particularly stressed due to lack of structure and predictability [10]. It is also difficult for the individual with a communicative disability to communicate with the staff and ask questions [10]. To a certain degree this is true also for other individuals, in particular those whose skills in the spoken and or written language that is used, are not enough, and also may lack knowledge of the culture of the health care system [11]. 
Children also may have difficulties in understanding and communicating during health care situations. The UN convention on the rights of the child states that all children should be equally treated and have the right to freedom of expression, including the right to seek, receive and impart information and idea in all forms [1]. Research has shown that this is not always the case in within health care. Coyne [12] has shown that children sometimes have the feeling of being excluded, not receiving information or being involved in decisions and often talked to in a language which is difficult to understand. The same study shows that children feel less worried, calmer and respected when they are provided with information and asked about the care [12]. According to [13] this also leads to an increased feeling of control which in turn leads to improved compliance and more effective care.

This means that far more people, than those with communicative disability, are in need of better support to access information and communication within the health care system. To develop routines, procedures and materials within health care, based on the idea of universal design, should benefit all groups both with and without communication problems. This would also save time and resources in the efforts of providing equal care to all [11].

\subsection{AAC to promote accessibility in health care situations}

Augmentative and alternative communication (AAC) includes all forms of communication (other than oral speech) that are used to represent thoughts, needs, wants, and ideas. AAC can be used both as a support for comprehension and for production of spoken or written communication [14].

Project activities concerning use of AAC as a tool in hospital care seem to be going on in many countries. However, when it comes to research of the effects of these interventions, specifically regarding children, very little has been done. In a review of research regarding communication between nurses and patients with complex communication needs $(\mathrm{CCN})$ undertaken by Finke, Light and Kitko [15], none of the twelve studies that were identified specifically concerned children. Another review that was found focused disabled children's experiences as inpatients [16]. The data, gathered from children, parents and staff in the eight qualitative studies that were reviewed, showed that communication was the overarching theme. Nurses reported that communication was difficult and that they did not have a consistent framework for involving the child in discussion and decision. The main conclusions comprised recommendations of giving the child information and appropriate involvement in discussion and decision-making and that the children's experiences with respect to this was not optimal. Despite the strong focus on communication in this review and the conclusions also pointing to the need of more training in communicative strategies, there is no mentioning or discussion of augmentative strategies or tools in this article. Beside these two reviews of communicative disability and hospital care, a pilot study published in 2013 report successful results using pictorial supports for children with autism in medical settings [17]. Two other studies report how AAC successfully can be used more generally in paediatric care. The first study was published by Costello in 2000 and presents the Children's Hospital Boston model of pre-operative AAC-intervention. This intervention prepares the children and the families for the expected period of loss of speech due to tracheostomy, intubation and/or use of ventilators during the postoperative care 
at the Intensive Care Unit (ICU). The results of the evaluation were excellent in that almost all patients used the communication aids they had chosen and loss of speech was not seen as the major problem, in contrary to most evaluations of ICU care [18]. In the second study a picture board was provided as a means to answer questions of pain after surgery. The children's answers were more precise using AAC and the parents were very positive [19].

In spite of these positive reports more efforts are needed. This was evident in a study by Thunberg, Buchholz and Nilsson [20], where parents of children with communication difficulties were interviewed (among these also parents to children on the autism spectrum). The parents stated that hospitals should be better both in providing various forms of communication materials and also in adapting these to different children and different situations.

In particular the parents stressed the importance of direct communication between the medical staff and the children, and that staff need more knowledge about communication and use of AAC to manage this. The staff need to communicate with the child on the child's own condition and should therefore receive training in the use of alternative and complementary means of communication and also how to interact with children with communication difficulties [20].

Unfortunately there is no research on how children with ASD or other types of communication problems perceive medical care. However, there are studies showing that adults with communication difficulties are experiencing a lack of communication competency in health care. Just as parents of children with communication disabilities, adults states that medical care staff need greater knowledge of and training in communication strategies and the use of alternative means of communication [21].

\subsection{KomHIT model - Communication support in paediatric and dental care}

The KomHIT model - communication in care settings using communicative support and IT has the overall purpose to improve the communicative rights of children with communicative disabilities during pediatric or dental care situations according to the Convention on the rights of persons with disability using AAC as Universal Design (article 3, United Nations, 2006). KomHIT therefore tries to implement AAC, mainly in the form of visual supports, generally to all or most children. This is important in today's care which often is slimmed with respect to time and resources, making it a challenge to implement procedures and methods that are exceptions to the daily routines. The basic idea is that "what is good for people with disability is good for everyone". When AAC or visual support is used generally, communication, clarity and safety is improved for everyone. This is particularly important for the group of children with disabilities and their parents who have another language-and/or cultural background. The model has been developed within a joint project involving both professionals and user organizations.

KomHIT consists of both educational resources and easy available communicative tools/ materials. A web tool has been created where pictorial communication material can be made, stored and searched by both professionals and parents (www.bildstod.se). The symbols that are available have been developed within different EU projects and can all be used for free, as long as they are not used commercially. This pictorial web tool www.bildstod.se can be said 
to constitute the main resource. The other web-resource (www.kom-hit.se) also shares information about (1) communicative rights according to the UN conventions on the right of the child and on persons with disabilities (2) project work and methods (3) relevant research (4) a video bank of illustrative video clips and links to external video material (5) a bank of educational resources and information about webb-based and campus-based courses and educations.

The educational model involves both campus-and web-based courses. Two basic packages for education has been developed. One to educate KomHIT communication mentors, and the other one to be used by the communication mentors in their job to guide and educate their colleagues. The education of mentors includes knowledge about communication, communicative disability, the UN convention on the right of persons with disability and augmentative and alternative communication strategies. This is given through lectures, video examples, role plays and exercises using and designing pictorial material and the web-resource www.bildstod.se. A choice of these resources are then provided to the mentor to pass on to their colleagues during meetings and/or educational activities within their clinics to implement the use of AAC/pictorial support. The majority of the educational resources are available on the KomHIT web site also to be accessed and used by other persons in need of communication support, specifically parents of children with communicative disabilities.

\subsubsection{KomHIT model - A pilot study within day surgery}

KomHIT was first pilot tested and evaluated on a day surgery ward at Queen Silvia Childrens' Hospital in Gothenburg, Sweden. All children/families were provided with (1) an invitation letter to the surgery ward with structured text and pictorial support, (2) a visual schedule with six pictures informing of the main events, (3) a communication board with 30 symbols to enable conversation on the topic of day surgery (figure 1). (4) A visual schedule book of 6 pages, depicting a vertical column of five photos/symbols each, showing the details of the procedures during the visit (figure 1). Information about the KomHIT project and the use of the materials was also attached to the invitation letter. The parents were instructed to point to the pictures while explaining and talking to the child about the hospital visit, and to bring the visual schedule along during the travel to the hospital. Upon arrival to the surgery ward the nurse used point talking to the pictures in the Schedule book explaining the procedures of the day. The child then could bring this book along during the day and remove the pictures one-byone after finishing the different steps. Each nurse also had access to the same "day surgery communication board" as was sent to the family (to the right above), to be able to expand point talking beyond the book, specifically for children with more comprehensive communication problems.

A pilot study of this intervention was conducted focusing on the expected decrease in stress and anxiety [22]. Twenty-five children with communicative disability (about half on the autism spectrum) and their parents participated (seven in the intervention group, 18 controls). Children and parents were asked about their emotional state using the State-Trait Anxiety Inventory (STAI), for children adapted to the Talking Mats format, and samples of saliva were collected. Premedication was also checked. Due to the few participants that could be recruited 

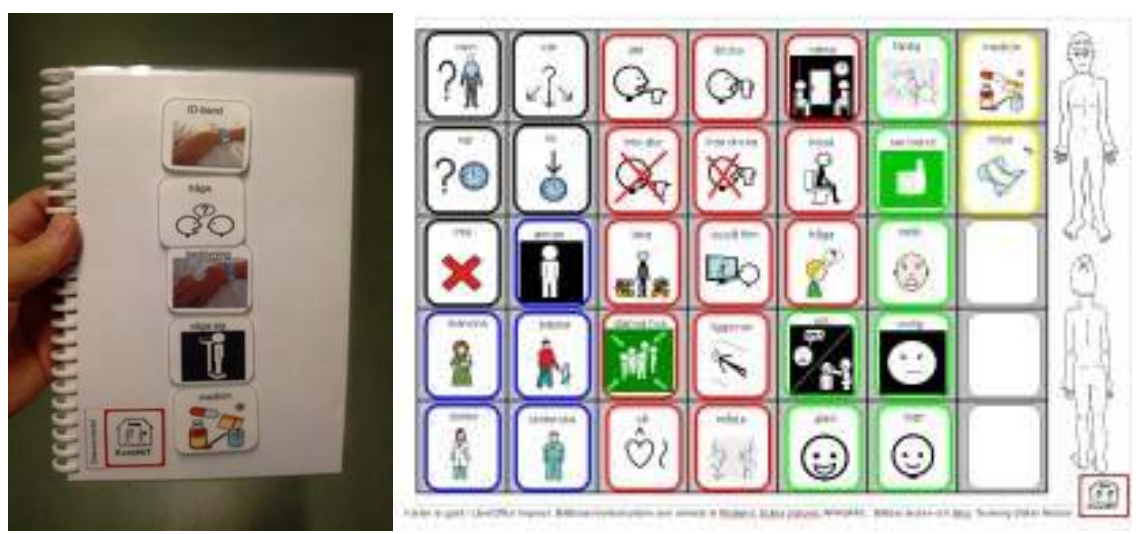

Figure 1. Examples of tools used within day surgery. To the left the visual schedule book of six pages depicting a vertical column of five photos on each side. The child removes the pictures one-by-one after finishing the different steps. This book was used for all children 2-8 years old and for older children with disability or language problems and/or being tense or anxious. The picture to the right shows a communication board that was used with children who needed more support during information and conversation.

during the intervention phase no statistical analyses could be done. The results were promising in that the morning cortisol levels were lower in the group of children who were provided with AAC and that none of these children were in need of premedication. No differences were seen in regard to the STAI results. It was discussed that this might be due to the adapted STAI being too rough a measure. In conclusion this pilot study indicated that the use of pictures can reduce anxiety in children with communicative disability during hospital care, but that more research is needed to prove this [22].

The following parts of this chapter describes the implementation and evaluation of the KomHIT-model in a Neuropsychiatric clinic, using AAC in the form of pictorial supports during assessment and intervention procedures.

\section{The KomHIT-model using AAC during assessment and intervention within neuropsychiatry}

\subsection{Implementation of the model}

The department that was involved in this study is part of the neuropsychiatric clinic at Queen Silvia children's hospital, a regional specialist hospital for children and adolescents in Sweden. This clinic mainly performs assessments and medical interventions for children and adolescents with suspected and diagnosed neuropsychiatric disorders. The main task of this particular department or team is to assess young (pre-school-aged) children, where the majority of the children have pervasive problems with communication. Due to the strong hereditary factor in neuropsychiatry several parents also have problems with communication. 
A comparatively large amount of the families also have another language and/or cultural background that complicates the understanding of information, instructions and also the health care system and Swedish society generally.

Two team members from this department, a speech-language therapist and a special educator, was enrolled in the development of the KomHIT model and was provided with the communication mentor education described above. In collaboration with the head of the department the planning of implementation was done. They started off by informing the staff about the overall purpose and methods of the KomHIT intervention and that they wanted to interview everyone about their processes, the need of pictorial supports and the design of these. After completing these interviews the designing of the supports or tools were done according to the wishes and ideas of the different team members.

The mentors had the opportunity to convene the staff to a kick-off - a half-day of training, going through convention texts, AAC methods and showing video clips of AAC-use in clinical situations. Each professional was provided with a folder with his/her own set-up of tools; visual schedules and dedicated communication boards and exercised the use of these in role plays. The two communication mentors also presented the general tools of the department; invitation letters with pictorial support, communication boards and visual schedules for waiting room communication, play activities and toilet visits, and finally visual support for identifying the different rooms. The materials that were developed are listed in the table below (table 1) and examples of these are displayed (figure 2).

The staff was asked to start the use of the visual tools and point talking immediately after the kick-off or as soon as possible. They were informed about the evaluation activities, a survey and a group interview, that was about to take place two months later and that it was important that they could participate in these.

\subsection{Pictorial supports and examples}

The materials that were developed are listed in the table below (table 1) and examples of these are displayed (figure 2).

\begin{tabular}{|c|c|c|}
\hline Type of material & Aim/name & Short description \\
\hline \multirow[b]{2}{*}{ Invitation letter } & Child invitation letter (figure 2) & Text and illustrating pictures. Sent home to the child \\
\hline & $\begin{array}{l}\text { Invitation letter with many } \\
\text { appointments }\end{array}$ & Text and illustrating pictures. Sent home to the family \\
\hline \multirow[t]{2}{*}{ Visual schedule } & Physician and nurse & $\begin{array}{l}\text { Pictures to be selected and used on a visual schedule } \\
\text { during the visit and that could be removed after finishing } \\
\text { the different steps }\end{array}$ \\
\hline & Sampling and measuring & $\begin{array}{l}\text { As above - more specific for sampling: blood, weighing } \\
\text { and measuring }\end{array}$ \\
\hline
\end{tabular}




\begin{tabular}{|c|c|c|}
\hline Type of material & Aim/name & Short description \\
\hline & Medication school & $\begin{array}{l}\text { Pictures to be used within the clinic's medication school } \\
\text { where the children are taught how to manage their } \\
\text { medications }\end{array}$ \\
\hline & ADOS & $\begin{array}{l}\text { Pictures to support procedures and instructions in regard } \\
\text { to ADOS assessment }\end{array}$ \\
\hline & Speech-language therapist & $\begin{array}{l}\text { Pictures to support procedures and instructions in regard } \\
\text { to assessment and intervention }\end{array}$ \\
\hline & Psychologist (figure 2) & $\begin{array}{l}\text { Pictures to support procedures and instructions in regard } \\
\text { to assessment and intervention }\end{array}$ \\
\hline & Literacy testing & $\begin{array}{l}\text { Pictures to support procedures and instructions in regard } \\
\text { to assessment of reading and writing }\end{array}$ \\
\hline \multirow{5}{*}{ Communication board } & Large general (figure 3) & $\begin{array}{l}\text { Larger board that could be used generally to support } \\
\text { communication/conversation and other more specific tools }\end{array}$ \\
\hline & Small general & $\begin{array}{l}\text { Smaller board that could be used generally to support } \\
\text { communication/conversation }\end{array}$ \\
\hline & $\begin{array}{l}\text { Small specific speech-language } \\
\text { therapy }\end{array}$ & $\begin{array}{l}\text { Smaller board to be used more specifically during speech- } \\
\text { language therapy visits }\end{array}$ \\
\hline & Doctor's bunch (figure 3) & $\begin{array}{l}\text { A bunch of small boards to be used by the doctor to } \\
\text { support communication/conversation }\end{array}$ \\
\hline & Specific doctor and nurse board & $\begin{array}{l}\text { Two smaller boards to be used more specifically during } \\
\text { medical visits }\end{array}$ \\
\hline \multirow{14}{*}{$\begin{array}{l}\text { Waiting room/ } \\
\text { environment }\end{array}$} & Car play & Board to support car play communication \\
\hline & Doll play & Board to support doll play communication \\
\hline & Duplo play & Board to support duplo play communication \\
\hline & Garage play & Board to support garage play communication \\
\hline & Play House & Board to support Play house communication \\
\hline & Reading story books & Board to support story book reading \\
\hline & Choosing play activity & Board to support pay and choice-making \\
\hline & Waiting room & Board to support waiting-room communication \\
\hline & Cloak room & Board to support cloak room communication \\
\hline & Schedule for clothing & Visual schedule for taking on/off clothes \\
\hline & Schedule for toilet & $\begin{array}{l}\text { Visual schedule for toilet procedures, available in two } \\
\text { formats: less and more detailed }\end{array}$ \\
\hline & Welcome instructions & $\begin{array}{l}\text { Text and illustrating pictures to welcome patients and } \\
\text { parents and provide instructions (available in different } \\
\text { formats for the different waiting-rooms) }\end{array}$ \\
\hline & Missed appointments & $\begin{array}{l}\text { Text and illustrating pictures to inform about } \\
\text { consequences of not cancelling booked appointments }\end{array}$ \\
\hline & $\begin{array}{l}\text { Symbols/pictures for visual } \\
\text { marking-up }\end{array}$ & $\begin{array}{l}\text { Symbols/pictures for marking-up rooms an functions on } \\
\text { the clinic }\end{array}$ \\
\hline
\end{tabular}

Table 1. List of pictorial material that was developed on the Neuropsychiatric clinic 

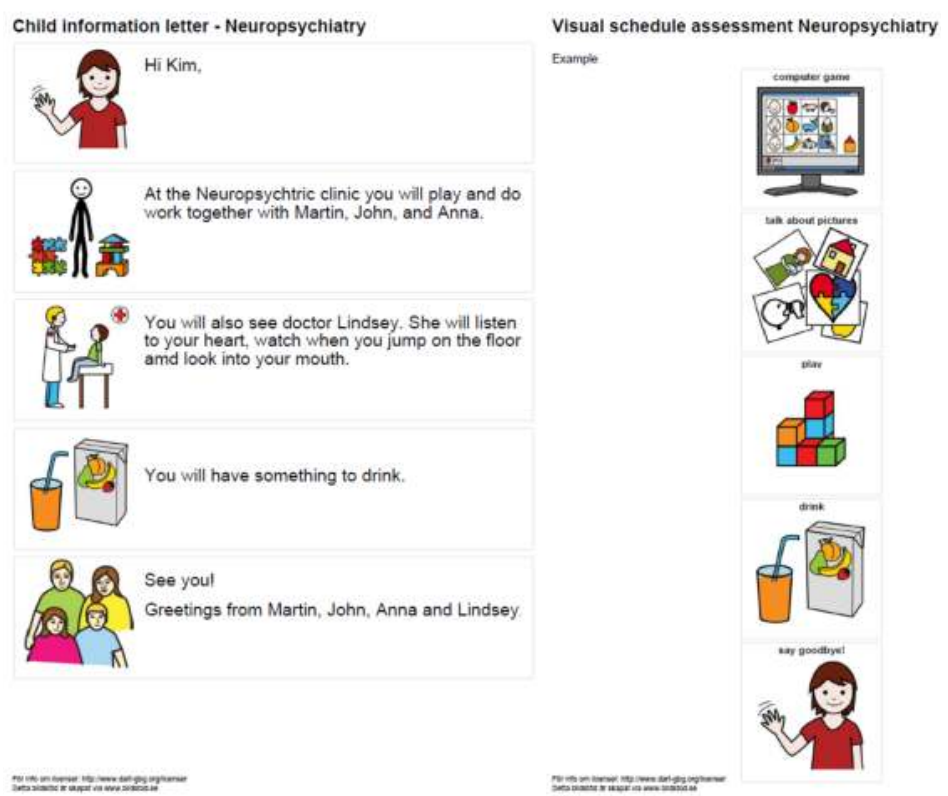

Figure 2. Examples of the pictorial materials listed above. To the left an invitation to the child. To the right a visual schedule for an assessment session. More material are available at www.kom-hit.se
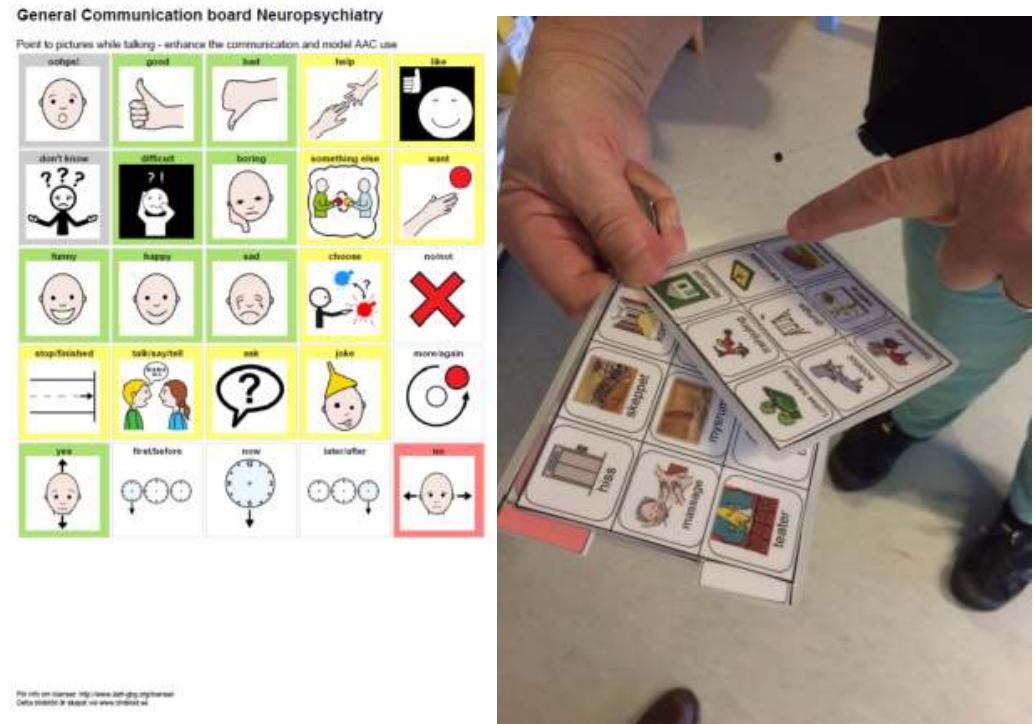

Figure 3. Examples of the pictorial materials listed above. To the left a general communication board to be used in different situations. To the right a bunch of boards dedicated for the physician. 


\section{Evaluation and results}

The evaluation was done through a survey distributed to staff and parents at the department and through a group interview with staff members. The survey was part of the general evaluation activities that was completed on all clinics involved in KomHIT and will not be reported here. The group interview used a semi-structured format along the lines of focus group methodology [23] and a content analysis of the transcripts was carried out to identify categories and main themes [24].

\subsection{Participants}

The participants in the focus group study was recruited from the department working with young pre-school aged children on the child neuropsychiatric clinic at Queen Silvia Children's Hospital, a regional specialist hospital in Sweden. This department was selected since the vast majority of the patients had communicative problems, were in need of communicative support that was only occasionally provided before the intervention started. An invitation letter with information about the interview was distributed to the entire staff at the department. A group of six staff representing five professions was recruited. Participant data is presented in table 2 .

\begin{tabular}{|c|c|c|}
\hline Participant & Gender & Profession \\
\hline P1 & $0^{x}$ & Physician \\
\hline P2 & 우 & Psychologist \\
\hline P3 & q & Speech language therapist \\
\hline $\mathrm{P} 4$ & 우 & Special educator \\
\hline P5 & 오 & Nurse \\
\hline P6 & 우 & Special educator \\
\hline
\end{tabular}

Table 2. Participants

The initial purpose was also to carry out a group interview with parents. Although many parents were positive to participate in such an interview this idea finally had to be put off due to practical problems.

\subsection{Procedure}

The group interview was carried out by the second and third author. One interviewer had the role as moderator and was responsible for introducing new topics and lead the interview, and also to hold a short summary at the end of the interview. The second interviewer was responsible for the sound recording and took notes during the interview. The sound recording was carried using an iPhone 4 with iOS 7 and a Samsung Galaxy S4 with Android version 4.3. A 
pilot interview was first completed to practice the allocation of roles and responsibilities. Four speech language therapy students was interviewed of how the speech language therapy program prepares the student for working life.

The interview took place at the neuropsychiatric clinic. The participants all filled out a consent form also containing a question about their earlier experiences of pictorial supports. An interview guide was used. The issues were linked to the survey the staff recently had completed and focused the health professionals', parents' and children's views about the KomHIT materials. The children's and parents' degree of anxiety and possibility to be active and to participate during care and through the use of pictorial support was also discussed. The guide was used as a support for the moderator to hold the group on focus and in presenting the issues. Open-ended questions were used. A stimulus material consisting of examples of the pictorial supports, was placed on the table to help the participants stay on focus [23]. The moderator redirected the discussions when they were considered as drifting away too far from the targeted topics. At the end of the interview, the moderator summarized what had been said and the participants were given the opportunity to make clarifications [23]. The interview lasted for approximately one hour.

\subsection{Transcription and analysis}

The audio recordings from the interview was transcribed ortographically. Focus was on content rather than interaction patterns. The transcription was done at Level III, which meant that the utterances were transformed to complete sentences that began with a capital letter and ending with appropriate punctuation. Unfinished sentences, repetitions and hesitations were removed. Pauses and laughter was not marked [23]. Transcription Level III was chosen to facilitate for the participants to read through the transcription. The authors transcribed half of the sound recording each and then read through each part of the transcription, and compared with the audio recording. As a final step the authors listened to and discussed the pieces that were difficult to hear until consensus was reached. In the transcripts, participants were given a code and the names of individuals and entities were removed. The transcription was sent to the participants who had the opportunity to read, review and then approve it. Participants had a week to come back with changes. Participants were only allowed to revise their own utterances. The revision process proceeded until the participants were satisfied. One of the participants clarified some opinions, but did not remove any information. No other changes were made.

Qualitative content analysis according Graneheim and Lundman [24] was applied as a method of analysis. In the present study manifest content, ie content that is expressed directly and does not need interpretation, was in focus. Each step in the analysis was conducted jointly by the authors. To get an overview and to obtain an overall impression the authors began by reading the transcript several times. The transcription was inserted into a table in a word processing program and then divided into meaning-bearing units. This meant that utterances involving several topics were divided into smaller units. Utterances that was on other topics or lacked relevant content was deleted from the analysis. In case of disagreement about this, the authors listened to the audio recording until consensus was reached. The meaning-bearing units were 
then condensed with the purpose of obtaining the core without affecting the content. The next step was to code the condensed units. The codes were printed, spread out on a table and then grouped in different categories based on their content. As the last step in the analysis, the categories were grouped together to form themes. When disagreements arose the authors first consulted the transcription and as a next step the audio recordings and discussed until consensus was achieved.

\begin{tabular}{|c|c|c|c|c|}
\hline Meaning-bearing units & $\begin{array}{l}\text { Condensed } \\
\text { units }\end{array}$ & Codes & Categories & Themes \\
\hline $\begin{array}{l}\text { I think it helps to play down } \\
\text { also it is not so mysterious. }\end{array}$ & $\begin{array}{l}\text { It helps in making it more } \\
\text { concrete and less } \\
\text { mysterious }\end{array}$ & $\begin{array}{l}\text { The information } \\
\text { letter demystifies }\end{array}$ & Preparation & $\begin{array}{l}\text { Pictures } \\
\text { before visit }\end{array}$ \\
\hline $\begin{array}{l}\text { But it is only within pediatric } \\
\text { care you are thinking. Because I } \\
\text { belive in geriatrics and in care } \\
\text { for the elederly, as they get old, } \\
\text { there must surely be. I believe } \\
\text { this would be great. }\end{array}$ & $\begin{array}{l}\text { I'm thinking of care for the } \\
\text { elderly, when people are } \\
\text { older this would be useful }\end{array}$ & $\begin{array}{l}\text { Pictures should be } \\
\text { used within } \\
\text { geriatrics }\end{array}$ & $\begin{array}{l}\text { Pictures in other } \\
\text { areas of care }\end{array}$ & $\begin{array}{l}\text { The need of } \\
\text { pictures in } \\
\text { health care }\end{array}$ \\
\hline
\end{tabular}

Table 3. Overview of the process of the content analysis and two examples

Credibility in this qualitative content analysis concerns how well the themes and categories were consistent with the transcribed data. One way to show this that also was used in this text, is to present representative quotations from the transcribed material [24]. This means that the data processing is presented in an explicit and transparent way, which facilitates the examination of the credibility [25]. An external check of the analysis was also conducted [23]. A senior speech language therapy student read twenty percent of the transcription and compared the content to the analysis and the identified codes, categories and themes. The external assessor found that the identified themes and codes were in concordance with the text except for one utterance that the authors had excluded as not being relevant. This was taken into account by the authors, who returned to the audio recording to ensure proper assessment.

\subsection{Result}

The content analysis of the interview data resulted in 18 identified categories that could be merged into 7 themes. These were: pictures used preparatory before healthcare visits, pictures used during healthcare visits, design, use, guidance, reactions in children, and the need of pictures in health care (see Table 4). Each theme and the included categories are described below in the text and used as titles. Examples from the transcribed texts, printed in italics, are presented for the majority of the categories. 


\begin{tabular}{ll}
\hline Themes & Categories \\
\hline Pictures used preparatory before health care visits & Support for parents \\
\hline Pictures used during health care visits & Preparation \\
\hline & Pictures in waiting room \\
\hline Impact on testing \\
\hline Development of materials & Learning \\
\hline Structure \\
\hline Participation \\
\hline Guidance & Digital pictures \\
\hline Reactions in children & Form \\
\hline The need of pictures in health care & Developmental and pictorial level 1 \\
\hline & Opportunities for use \\
\hline & Pictures as a resource \\
\hline & Health care professionals as models \\
\hline & Generalisation \\
\hline & Anxiety \\
\hline Interest \\
\hline Previous need for pictures \\
\hline
\end{tabular}

Table 4. Themes and categories identified in the content analysis

\subsubsection{Pictures used preparatory before health care visits}

\subsubsection{Support for parents}

The staff thought that the pictures was a support for the parents. The staff expressed the opinion that the parents' anxiety seemed to be reduced when they had been provided with the invitation letter with pictures and then had more information about what was about to happen during the visit. The pictures seemed to serve as a tool for the parents to explain what will happen to their children. The staff expressed that the invitation letter could play an important role for parents of young children and also for parents with insufficient understanding of Swedish.

"... I mean it is a support for the parents as well, explaining to the children, in that they have access to the pictures, so in that way I believe it's very positive."

\subsubsection{Preparation}

The nursing staff thought the invitation letter made both children and parents feel safe because they know what will happen and who they are going to meet. The staff experienced that the parents were more prepared and better informed. The invitation letter made the visit less mysterious.. According to the staff, several parents had expressed that they appreciated the pictorial invitation letter. 
"We really enjoyed to look at the pictures and checked, what's going to happen, well who is this, and so on. I believe this actually is good."

\subsubsection{Pictures used during health care visits}

\subsubsection{Pictures in waiting room}

Only a few of the staff had used the waiting room boards, but told that some parents had commented that the pictures were funny and that the children liked them. These boards may not be have been used in the best interest of the children because the parents were not accustomed to the use of pictorial support. The staff stressed that in spite of this the pictures still were important in demonstrating an approach to support communication.

\subsubsection{Impact on testing}

Some of the staff felt that the use of pictorial support could influence the evaluation and testing results. The perception was that the pictures facilitated the testing too much so that the purpose of some of the tests could not be fulfilled. The staff expressed that during the assessment of the child's communication skill the pictures should be used to enable the child to participate in the test situation but not to communicate. However, in some test situations pictures could not be used at all. Pictorial support was considered to be easier to use in a treatment situation.

"I can imagine it [visual schedule] would affect the ADOS-result. One would think, but if he had not pictorial support how he had reacted when..."

\subsubsection{Learning}

Most children and parents were unfamiliar with the use of pictorial supports. The staff expressed that it was problematic that they saw the children only occasionally and too little to really have them understand the use of the pictures, specifically those at early developmental stages. The staff thought it was easier for the children and parents to understand the use of the pictures if they consistently were provided with pictorial support in invitation letters, waiting rooms and personal interaction. The staff thought the children could gradually learn the meaning if they were recurrently exposed to the pictures and if the staff used a rich body communication to assist the children's understanding.

\subsubsection{Structure}

The staff felt that they did not need to use the visual schedule so often, but that it was great to use with children who have attention difficulties. For these children, the pictures provide structure and help to focus. The children also are provided with a concrete idea of how far they have proceeded during the visit.

"... And said, yes, but we're going to do this, and lined up the pictures so that the child can imagine. Yes now we can remove this, now we can take that one away. Then they are assisted in coping". 
Staff however also had the opinion that the pictures sometimes made them less flexible. They felt that they had to stick to the schedule, even when it was less well adapted. When they used pictures that were not so specific, it was easier to change the order during the visit.

\subsubsection{Participation}

The picture schedule seemed to facilitate participation for some children during examination or testing. The pictures could be used to direct the children's attention to something and to have children who were restless to sit down. Staff discussed that the situation could be perceived as less demanding when pictorial tools were used. A picture schedule was considered to give children control over the situation. Through the use of images the children had freedom to express what they wanted to do. The images had enabled communication between children and the staff, and had been used by the child to ask questions.

"And a little control of the situation as well, then you do what he picture says, and will not come up with something else that I do not know what it is. And you have the freedom of saying, that and that, and that I do, but not this."

\subsubsection{Development of materials}

\subsubsection{Digital pictures}

Having access to pictures using a smartphone or tablet was considered to simplify the work. Being able to find exactly the correct one quickly was seen as an advantage. Children who were not interested in pictures might think they were more funny and interesting if they were presented on a phone or tablet. However, the staff also discussed the risk that the tablet could be associated with gaming or play. Therefore alternate forms for presentation of the pictures are needed for different children.

\subsubsection{Form}

The group also discussed the size of the images and some thought that the images being used were too small. Size and degree of detail of the pictures differs on an individual basis. The nursing staff did not think that it was necessary to use a particular or specified picture/symbol system but that it instead was the way of thinking that was important.

\subsubsection{Use}

\subsubsection{Developmental and pictorial level}

The staff thought that the pictures they used right now worked best with the children at more advanced level of development. For children at earlier stages, it could be difficult to understand the picture and associate it to the activity. Options should be available that would be more easy to use for these children, such as photographs and objects. The staff had the idea, that to be able to use a picture as a resource, it is not necessary to have a full understanding of the picture. To be able to focus the picture is more important. The staff must be quick in deter- 
mining whether pictures would work for a specific child. Staff expressed that it was difficult to find and use pictures for more abstracts concepts.

"... Sometimes it doesn't mean anything to the children, the young children /... lare sometimes on a concrete level..."

\subsubsection{Opportunities of usage}

The staff discussed during which occasions the pictures were best used. Some had the opinion that the picture schedules were difficult and unnatural to use for testing or assessment. Instead they were considered to be easier to use during intervention and more concrete activities, such as weighing and measuring the child. In some situations pictures were not used at all by the staff, either because an enhanced use of body communication was considered sufficient or that the sometimes long experience of working with children with neuropsychiatric disorders made them manage without. On the other hand experience in using pictures was considered to facilitate the use of pictorial support:

"but I believe that it is good if you use it (pictorial support) continuously to feel comfortable and relaxed"

The opinion of the staff was that pictures was a great resource for those children who had difficulties with eye-gaze contact. To jointly watch the pictorial aid could be a way to establish contact without the need of direct eye-contact. The transition from the waiting-room to the examination-room was also considered to be facilitated through the use of pictures.

\subsubsection{Pictures as a resource}

The staff thought that the pictures generally made their work with the children easier. The pictures were looked upon as a resource or a tool that could be used when there was a need, for example when they got stuck out of some reason. Pictures did not always help out in these situations, but on the other hand never did any harm either

.... It is a privilege to have this resource and it is such a useful aid..."

\subsubsection{Guidance}

\subsubsection{Healthcare professionals as models}

The staff felt that they could act as models for the parents so they could observe how pictures could be used in interaction with their children in everyday life. When the staff used pictures, this no longer seemed so strange or dangerous. The staff expressed that the parents often became positive when they could see themselves how the use of pictures facilitated the staff's communication with their child.

"... And see that it actually increases, yes it may well increase the child's understanding and ability to come up with something and show..." 


\subsubsection{Generalisation}

The nursing staff wished to have access to pictorial supports or tools for various activities and games to give to parents in facilitating generalization to the home environment. According to the staff, parents are in need of concrete support to be able start up in practice as soon as they showed that they wished or wanted to. This was also clearly expressed by the parents. The staff thought it would be easier to show how pictures could be used and to answer parents' questions if they could provide the parents with some ready-made materials.

"Because they [the parents] kind of kick-offs mentally and get concrete ideas after they have had the opportunity to start up with something."

The staff had the opinion that the generalization to the pre-school environment often was good due to the fact that many pre-schools already used pictorial tools. The staff only had to encourage these pre-schools in enhancing their use of visual support and sometimes also demonstrate the use.

\subsubsection{Reactions in children}

\subsubsection{Anxiety}

The nursing staff believed that the pictorial supports decreased anxiety in both children and parents. In particular, the pictorial invitation letter was considered to reduce the child's anxiety in that the child was provided with information about what was about to happen that was easy to understand. Sometimes when a child was anxious or restless the staff also could get back to this letter and go through what was going to happen. The staff was convinced that clear information reduced anxiety in children with autism. They also believed that pictorial support should be used with an increased number of children since most children would benefit from this.

"... We do not know how much it reduces anxiety during some visits, I think. I think, for you, for example, you know when you to go to the nurse, 'oh they won't do anything that I don't allow, for example."

\subsubsection{Interest}

The staff told that many of the children were very interested in the pictures. They were curious and perceived the pictures as fun and exciting. The staff expressed that the pictures added a sense of playfulness to the visits at their clinic.

"It gets a little bit more exciting and appealing to kids when pictures are used in some way.

They become more curious..."

\subsubsection{The need of pictures in health care}

\subsubsection{The previous need for pictures}

According to the opinions of the staff there had been a need for pictorial support on the clinic long before the project was started. Parents had asked for photos of the staff and for information 
about what would happen during the visits. The staff had experienced difficulties in describing this in a concrete way, which now easily could be done using pictures in the invitation letter. The staff meant that texted information only, could not generate the same type of conversations between parent and child as now was the case. Without the pictures it was more difficult for the parent to explain to the child what would happen. Some of the staff had previously created their own pictorial support by drawing or using photos when they felt that this was needed.

"And there was a need for this because I used to say to the parents when I met them the first time that you can take a photo of me with your phone and show to the child..."

\subsubsection{Pictures in other areas of care}

The staff believed that the use of pictorial support was something that had come to stay within health care. They expressed that pictures would be good to use outside of pediatrics, for example within geriatrics, and with people with aphasia.

\subsection{Further research}

To further investigate the role of pictorial support in health care and within neuropsychiatric clinical work, it would be interesting to do a controlled group study comparing both communication and other aspects of care with and without the use of pictorial support. Doing a similar study like this, but with a larger number of respondents and interviews with children, parents and health professionals from different clinics that strengthen and further develop these results, is also important. It would also be interesting to study and compare the results for different groups of children - of varying age, diagnosis, communication profiles-and for different activities and types of pictorial supports.

\section{Conclusion}

This study is one of the first that describes an intervention aiming at increasing the communicative rights of children within the autism spectrum during clinical assessment and intervention. The pilot evaluation in the form of an interview with the multiprofessional team provides valuable information on how work with pictorial supports can function in practice.

The staff was generally very positive and expressed that the pictorial supports facilitated communication. The materials made both children and parents better prepared for the visits and the clinical procedures. The children liked the concrete visual material that also seemed to provide them with a higher degree of control in the situation. The children were more focused when the pictures were used and both children and parents also seemed to be more relaxed. However, it also emerged that there are still shortcomings and that further development is needed. The staff expressed the opinion that it was easier to use the pictorial supports in concrete activities, such as medical procedures, compared to for example assessments. Children at really early stages of development could not benefit so much of the existing materials but instead probably are in need of a more individually adapted support, as are some 
other children as well. It was also possible to see that some opinions of the staff were contradictory. For example, it was expressed that they as professionals in the field did not need pictorial support very often, but that many more children than expected were in need of pictures. This might be a symptom of the fact that this was a new intervention that had not been used for long.

Finally and in spite of this, the staff expressed that the use of pictures "have come to stay", both at their own clinic but also elsewhere within health care. They meant that the number of people that benefit of the use of visual support are much larger than could be imagined.

\section{Acknowledgements}

The major parts of this chapter was part of an unpublished Masters' thesis in Speech language pathology at University of Gothenburg, June 2014. Thanks to patients, parents and staff at the Neuropsychiatric clinic at Queen Silvia Children's Hospital in Gothenburg who took part in the study, specifically Julia Eldblom and Ulrika Johansson who developed all pictorial materials, educated and inspired their colleagues. Thanks also to all members in project KomHIT including the Association for people with autism and Asperger syndrome in the Gothenburg region. KomHIT is funded by the Swedish Heritage Foundation. The writing of this chapter was funded by the Research Foundation at Queen Silvia Children's Hospital.

\section{Author details}

Gunilla Thunberg*, Magdalena Johansson and Julia Wikholm

*Address all correspondence to: gunilla.thunberg@vgregion.se

DART - centre for AAC and Assistive Technology, Sahlgrenska University Hospital, Sweden

\section{References}

[1] United Nations. United Nations Convention on the Rights of the Child (UNCRC), Geneva: United Nations 1989.

[2] United Nations. Final report of the Ad Hoc Committee on a Comprehensive and Integral International Convention on the Protection and Promotion of the Rights and Dignity of Persons with Disabilities 2006.

[3] Short C, Schopler E. Factors relating to age of onset in autism. Journal of Autism and Developmental Disorders 1988; 18 207-216. 
[4] Carr EG, Levin L, McConachie G, Carlson JI, Kemp DC, Smith CE. Communicationbased intervention for problem behavior. Baltimore, MD: Paul H. Brookes Publishing; 1997.

[5] Bryson S. Brief report: Epidemiology of autism. Journal of Autism and Developmental Disorders 1996; 26, 165-167.

[6] Bryson S, Clark BS, Smith TM. First report of a Canadian epidemiological study of autistic syndromes. Journal of Child Psychology and Psychiatry 1988; 29, 433-445.

[7] Lord C, Risi S, Pickles. Trajectory of language development in autism spectrum disorders. In R. M \& S. Warren (Eds.), Developmental language disorders: From phenotypes to etiologies (pp. 7-29). Mahwah, NJ: Lawrence Erlbaum; 2004. developmental perspective pp. 109-141. Baltimore, MD: Paul H. Brookes Publishing; 2000.

[8] Tager-Flusberg H, Joseph R, Folstein S. Current directions in research on autism. Mental Retardation and Developmental Disabilities Research Reviews 2001; 7, 21-29.

[9] Mahon M, Kibirige M S. Patterns of admissions for children with special needs to the paediatric assessment unit. Archives of Disease in Childhood 2004; 89, 165-169. doi: 10.1136/adc.2002.019158.

[10] Vaz I. Improving the management of children with learning disability and autism spectrum disorder when they attend hospital. Child: care, health and development 2010 ; 36(6), 753-755. doi:10.1111/j.1365-2214.2010.01144.

[11] Blackstone SW. Communication access across the healthcare continuum. Augmentative Communication News 2009; 21(2), 1-5.

[12] Coyne I. Consultation with children in hospital: children, parents' and nurses' perspectives. Journal of Clinical Nursing 2006 ; 15(1), 61-71. doi: 10.1111/j. 1365-2702.2005.01247.x

[13] Darby C. Cardwell P. Restraint in the care of children. Emergency Nurse 2011; 19(7), 14-17.

[14] Beukelman DR, Mirenda P. Augmentative \& Alternative Communication (4th Edition). Baltimore 2013: Paul H. Brookes Publishing Co.

[15] Finke E H, Light J, Kitko L. A systematic review of the effectiveness of nurse communication with patients with complex communication needs with a focus on the use of augmentative and alternative communication. Journal of Clinical Nursing 2008; 17(16), 2102-2115. doi: 10.1111/j.1365-2702.2008.02373.x

[16] Shilling V, Edwards V, Rogers M, Morris C. The experience of disabled chil-dren as inpatients: a structured review and synthesis of qualitative studies reporting the views of children, parents and professionals. Child: care, health and development 2012; 38(6), 778-788. doi:10.1111/j.1365-2214.2012.01372.x 
[17] Chebuhar A, McCarthy AM, Bosch J, Baker S. Using Picture Schedules in Medical Settings for Patients With an Autism Spectrum Disorder. Journal of Pediatric Nursing 2013; 28 (2), 125-134.

[18] Costello JM. AAC intervention in the intensive care unit: the children's hospital boston model. Augmentative and Alternative Communication 2000; 16(3), 137-153. doi: 10.1080/07434610012331279004

[19] Mesko PJ, Eliades AB, Christ-Libertin C, Shelestak D. Use of picture communication aids to assess pain location in pediatric postoperative patients. Journal of Perianesthesia Nursing 2011; 26(6), 395-404. doi: 10.1016/j.jopan.2011.09.006

[20] Thunberg G, Buchholz M, Nilsson S. Strategies that assist children with communicative disability during hospital stay-parents' perceptions and ideas 2014. Submitted for publication.

[21] Balandin S, Hemsley B, Sigafoos J, Green V. Communicating with nurses: The experiences of 10 adults with cerebral palsy and complex communication needs. Ap-plied Nursing Research 2007; 20(2), 56-62. doi:10.1016/j.apnr.2006.03.001

[22] Thunberg G, Törnhage C-J, Nilsson S. Can the effects of an AAC intervention be measured physiologically? A pilot study of communicatively disabled children undergoing day surgery. Submitted for publication 2014.

[23] Wibeck V. Fokusgrupper (2:nd Ed). Lund 2010: Studentlitteratur.

[24] Wibeck V. Fokusgrupper (2:nd Ed). Lund 2010: Studentlitteratur.

[25] Halkier B. Fokusgrupper. Malmö 2010: Liber AB. 
